\title{
IbM KELOMPOK BIMBINGAN BELAJAR DI KELURAHAN BANDUNGREJOSARI DAN BAKALANKRAJAN KECAMATAN SUKUN MALANG JAWA TIMUR
}

\author{
Marsuki $^{1)}$, Rokhyanto ${ }^{2)}$, Welas Listiani ${ }^{3)}$ \\ IKIP Budi Utomo Malang, Jalan Simpang Arjuno 14B Malang \\ 1) email: marsukigani@yahoo.com \\ 2) email: rochyanto_mhum@yahoo.co.id \\ 3) email: welas_listiani@yahoo.com
}

\begin{abstract}
The study aims at forming larning group and improving students' learning achievement of the elementary, junior, and senior schools at villages Bandungrejosari and Bakalankrajan Kecamatan Sukun Malang. The study uses quantitative-qualitative descritptive approach. The subjects are 15 local peopleas IbM cooperative partners trained to be learning counseling instructors and (2) 138 elementary , 18 junior, and 14 senior high school students joining with learning group and learning counseling at villages Bandungrejosari and Bakalankrajan kecamatan Sukun Malang. The instruments are observation sheet and test consisting of pretest and posttest. Based on the result achieved, the IbM program got extraordinary encouragement and symphaty from local people, villages, schools, and social leaders. The learning counseling activity was going on for 3 months from September 1 to November 29, 2014. Based on the test analysis, it was found that learning group formation by providing learning counseling could give significant influence which could be shown in that the mean of the posttest was higher than that of pretest for the students of elementary, junior, and senior schools at villages Bandungrejosari and Bakalankrajan kecamatan Sukun Malang.
\end{abstract}

Keywords: group, counseling, learning, achievement, partners.

\section{PENDAHULUAN}

Kota Malang selain dikenal sebagai kota pariwisata dan budaya, juga dikenal sebagai kota pendidikan. Kota inilah diyakini oleh masyarakat sebagai kota yang dapat menjadi wahana untuk meningkatkan prestasi belajar siswa. Namun kenyataannya, prestasi belajar siswa di kota ini mengalami perkembangan pasang surut dari tahun ke tahun. Pada tahun ajaran 2011/2012 yang lalu, prestasi belajar siswa di kota Malang menurun, tidak menunjukkan tren positif, dan dinilai gagal khususnya pada jenjang SMP/MTs dan SMA/MA/SMK. Fakta ini terbukti dengan banyaknya siswa yang tidak lulus ujian nasional (UN) hingga mencapai 38 siswa SMP/MTs dan 22 siswa SMA/MA/SMK (Malang Post, 2012). Dan yang paling menyedihkan dan memprihatinkan hasil ujian nasional
(UN) SMA/MA/SMK dan sederajat tahun ajaran 2011-2012, di Kota Malang menenpati peringkat ke 35 dari 38 kota dan kabupaten se-Jawa Timur (Malang Kompas.Com, 2013).

Pada tahun ajaran 2013-2014, hasil NUN siswa SMP di kota Malang menurun dengan nilai rata-rata 34,65 dibandingkan dengan tahun ajaran sebelumnya 2012-2013 dengan nilai ratarata 34,75. Terkait dengan hasil ini, Sekretaris Musyawarah Kerja Kepala Sekolah (MKKS) SMP Negeri, RV Sudharmanto, menuturkan, ada banyak faktor yang melatar belakangi menurunnya prestasi siswa. Salah satunya ialah masalah pendanaan.Ada siswa yang tidak bisa menambah jam belajar dengan les karena terbentur masalah biaya di sekolah negeri, lanjutnya, dukungan financial dari wali murid juga tidak ada sehingga 
pengembangan belajar yang memerlukan dana tidak dapat dilakukan dengan optimal karena hanya mengandalkan dana pemerintah (Malang Pos, 2014). Sementara dari hasil kelulusan siswa SMA bahwa pada tahun 2014 ini tercatat 5 siswa yang tidak lulus.

Berdasarkan penelusuran dan fakta yang kami lakukan, siswa-siswa di kota Malang yang mengalami kemerosotan dalam prestasi belajar, umumnya mereka yang tidak mengikuti bimbingan belajar di luar jam sekolah sebagai pelajaran tambahan karena orang tuanya tidak mampu secara ekonomi untuk mengikutkan bimbingan belajar. Dengan menjamurnya lembaga bimbingan belajar (Bimbel), banyak siswa yang memanfaatkan pelayanan pendidikan ini dengan membayar sejumlah uang yang tidak sedikit.Tetapi hal ini tidak dialami oleh siswa-siswa yang berasal dari keluarga yang tidak mampu yang orang tuanya berpenghasilan rendah dan tidak tetap.Oleh karena itu, upaya meningkatkan mutu pendidikan melalui peningkatan prestasi hasil belajar siswa yang tidak mampu harus menjadi komitmen bersama antara pemerintah kota Malang, perguruan tinggi dan masyarakat sehingga cara ini diharapkan dapat meningkatkan prestasi belajar siswa dan dapat mengembalikan dan mempertahankan kota Malang sebagai kota pendidikan.

Program Iptek Bagi Masyarakat (IbM) ini yang dilakukan oleh tim IbM adalah Pengabdian Masyarakat Berbasis Pendidikan (PMBP) yang dirancang dan diwujudkan dalam program pembentukan kelompok-kelompokdan bimbingan belajar (Bimbel) sebagai pelayanan pendidikan gratis kepada siswa-siswa yang tidak mampudi kelurahan Bandungrejosari dan kelurahan Bakalankrajan kecamatan Sukun Malang dengan tujuan untuk mendongkrak dan meningkatkan penguasaan materi Ujian Nasional bagi siswa-siswa SD/MI kelas VI, SMP/MTs kelas IX dan
SMA/MA/SMK kelas XII, sementara siswa-siswa SD/MIkelas I-V, SMP/MTs kelas VII-VIII dan SMA/MA/SMK kelas $\mathrm{X}$-XI dibimbing untuk meningkatkan prestasi belajar dalam mengikuti Ujian Akhir Semester (UAS).Pembentukan kelompok-kelompok bimbingan belajar (Bimbel) ini dilakukan karena selama ini sangat jarang guru/instruktur yang mengadakan bimbingan belajar (Bimbel) khususnya di 2 kelurahan tersebut sehingga para siswa yang ingin mengikuti bimbingan belajar harus mencari bimbingan belajar di luar.

Dipilihnya kelurahan

Bandungrejosari dan kelurahan Bakalankrajan kecamatan Sukun didasarkan pada alasan-alasan berikut (1) banyaknya siswa yang berasal dari keluarga yang tidak mampu, (2) biaya bimbingan belajar yang tidak dapat dijangkau karena keterbatasan ekonomi orang tua, (3) kurangnya motivasi untuk berprestasi di kalangan siswa, (4) jarangnya guru/tentor yang melakukan bimbingan belajar, (5) tidak adanya kelompok-kelompok bimbingan belajar yang diberdayakan oleh masyarakat sendiri, (6) kurangnya perhatian orang tua terhadap prestasi belajar anaknya, dan (7) kurangnya dukungan aparat kelurahan terhadap peningkatan kualitas hasil belajar siswa.

Kecamatan Sukun adalah salah satu dari 5 kecamatan di kota Malang yang mempunyai 11 kelurahan yaitu kelurahan Bandulan, Karangbesuki, Pisangcandi, Mulyorejo, Sukun, Tanjungrejo, Bakalankrajan, Bandungrejosari, Ciptomulyo, Gadang, danKebonsari. Berdasarkan hasil survei, 2 (dua) kelurahan yaitu Bandungrejosari dan Bakalankrajan memiliki siswa yang banyak mengalami kemerosotan dalam prestasi belajarnya dan berasal dari kalangan keluarga dan orang tua yang tidak mampu dalam ekonomi. Berdasarkan deskripsi di atas, tujuan studi ini adalah untuk membentuk kelompok belajar dan meningkatkan 
prestasi belajar siswa SD/MI, SMP/MTs dan SMA/MA/SMK di Kelurahan Bandungrejosari dan Bakalankrajan Kecamatan Sukun Malang Jawa Timur.

\section{METODE}

Studi ini menggunakan rancangan pendekatan deskriptif kuantitatif-kualitaf. Subyek studi ini adalah (1) 15 warga setempat yang diajak bekerja sama sebagai Mitra kerja IbM yang telah diberdayakan dengan memberikan pelatihan dan pembekalan tentang metode dan teknik pembelajaran, penyusunan silabus, dan pengembangan materi ajar yang meliputi pelajaran Bahasa Indonesia, Matematika, dan Bahasa Inggris sebagai materi untuk bimbingan belajar agar nantinya mereka bisa menjadi instruktur untuk warganya sendiri dan (2) siswa-siswa SD/MI yang berjumlah 138 orang, 18 orang SMP/MTsN, dan 14 SMA/SMK yang mengikuti kelompok belajar dan bimbinga belajar dari warga kelurahan Bandungrejosari dan kelurahan Bakalankrajankecamatan Sukun Malang.

Instrumen yang digunakan untuk mengumpulkan data adalah observasi dan tes yang terdiri dari tes awal (pretest) untuk mengukur kemampuan awal siswa ketika mengikuti bimbingan belajar dan tes akhir (posttest) untuk mengukur tingkat keberhasilan akhir para siswa SD/SMP, dan SMA sebagai peserta kelompok belajar yang diadakan di kelurahan Bandungrejosari dan kelurahan Bakalankrajan kecamatan Sukun Malang.

Sedangkan data studi ini adalah hasil observasi dan hasil tes awal (pretest) dan tes akhir (posttest) seluruh peserta kelompok dan bimbingan belajar. Setelah data telah terkumpul, kemudian dianalisis dengan menggunakan analisis deskriptif kuantitatif-kualitatif.

\section{HASIL DAN PEMBAHASAN}

Sesuai dengan tujuan di atas, maka hasil studi akan memaparkan pembentukan kelompok belajar yang telah dilakukan, dan peningkatan prestasi belajar siswa SD, SMP, dan SMA sebagai peserta kelompok dan bimbingan belajar yang dilaksanakan selama 3 bulan pada tanggal 1 September hingga tanggal 29 November 2014 di kelurahan Bandungrejosari dan kelurahan Bakalankrajan kecamatan Sukun Malang. Hasil-hasil ini secara berurutan akan dipaparkan berikut ini.

\section{A. Pembentukan Kelompok Belajar \\ Sebelum pembentukan kelompok} belajar dilakukan, langkah pertama adalah melakukan persiapan dan sosialisasi kepada pihak kelurahan, lembaga sekolah setempat, para ketua RW dan RT, dan warga masyarakat kelurahan Bandungrejosari dan kelurahan Bakalankrajan kecamatan Sukun Malang. Dari sosialisasi ini, maka dukungan dan sanjungan positif berdatangan dari pihak kelurahan, lembaga sekolah, tokoh masyarakat dan seluruh warga kelurahan Bandungrejosari dan Bakalankrajan mengingat program IbM berpihak pada kepentingan masyarakat dan membantu mereka memberi kesempatan kepada para putera-puteri merekauntuk mengikuti program bimbingan belajar. Program bimbingan belajar gratis ini tentu membantu putera-puteri mereka mendapatkan tambahan pelajaran selain di sekolah serta membantu kesulitan siswa belajar.

Dari sosialisasi yang telah dimulai mulai bulan Maret 2014, Tim IbM telah mendapatkan 15 orang warga dari kelurahan Bandungrejosari dan Bakalankrajan sebagai sukarelawan dan mitra kerja Tim IbM untuk menjadi instruktur dalam kelompok belajar ini sekaligus untuk membantu warganya sendiri dalam mengatasi kesulitan belajarnya dan memberikan pelajaran tambahan di luar sekolah. Oleh karena itu, tugas utama Tim IbM ini adalah memberikan pemberdayan kepada 15 Mitra kerja IbM itu melalui pelatihan dan pembekalan tentang teknik dan metode 
pembelajaran, penyusunan silabus dan pengembangan materi ajar untuk program bimbingan belajar. Materi ajar yang telah disusun meliputi pelajaran Bahasa Indonesia, Matematika, Bahasa Inggris.

Selanjutnya Tim IbM bersama Mitra kerja dan juga dibantu oleh para mahasiswa IKIP Budi Utomo Malang bersama-sama melakukan pendataan peserta kelompok belajar dengan mendatangi orang tua siswa. Dari kegiatan ini akhirnya peserta yang mendaftar dari kelurahan Bandungrejosari dan Bakalankrajan kecamatan Sukun Malang dapat meliputi siswa SD yang berjumlah 138 orang, SMP 18 orang, dan SMA 14 orang. Jumlah keseluruhan peserta yang mengikuti kelompok belajar adalah 170 orang. Dari 170 orang ini, dapat dibentuk menjadi 16 kelompok belajar dengan rincian 12 kelompok belajar dari siswa SD, 2 kelompok belajar dari siswa SMP, dan 2 kelompok belajar dari siswa SMA. Pembentukan kelompok belajar ini didasarkan pada kriteria jumlah yang baku pada setiap kelompok belajar yaitu antara $15-20$ orang dengan waktu belajar 90 menit setiap harinya. Peserta dari setiap kelompok belajar dalam pelaksanaannya mengalami pertambahan dan pengurangan. Tetapi pada akhir kegiatan di bulan Desember 2014, para peserta dari siswa SD, SMP, dan SMA mengalami penyusutan yaitu SMA $30 \%$, SMP $10 \%$, dan SD 2\%

Berdasarkan hasil analisis, ditemukan bahwa banyak warga yang mengirimkan putera-puterinya untuk mengikuti kelompok belajar dan juga tidak sedikit warga yang tidak mengirimkan putera-puterinya pada kegiatan kelompok belajar. Berbagai alasan yang melatarbelakangi persoalan ini yaitu (1) karena ada kegiatan pelajaran tambahan di sekolah yang bersamaan, (2) mengikuti bimbingan belajar di luar (3) mengaji, dan (4) kurang adanya dukungan dan motivasi dari orang tua serta rendahnya minat dan motivasi siswa itu sendiri mengikuti kelompok belajar.Dari alasan ini, maka jadwal kegiatan belajar pada kelompok belajar yang sudah terbentuk dan terstruktur mengikuti dan menyesuaikan keinginan dan kemauan warga kelurahan tersebut. Jadwal kegiatan ini berlangsung dari sore jam $14.30-17.30$ dan dilanjutkan lagi mulai jam 18.15 - 21.00. Tentu, Tim IbM yang bekerja sama dengan para Mitra Kerja dari warga setempat mengikuti dan menyesuaikan jadwal peserta kelompok belajar.Tujuan melakukancara ini adalah agar kegiatan ini secara perlahan-lahan bisa mendapatkan simpati dari masyarakat sehingga mereka dapat termotivasi dalam mengirimkan putera-puterinya belajar.Selain itu, agar kegiatan ini dapat berlangsung sesuai dengan harapan dan tujuan.

Tim IbM dan Mitra Kerja yang dibantu oleh mahasiswa berusaha semaksimal mungkin, tetapi hasil yang didapat adalah sejumlah itu. Ada beberapa alasan mengapa siswa SMA dan SMP kurang begitu banyak :

1) Mereka merasa malu dan gengsi untuk datang ke tempat kelompok belajar di tempat sekitarnya terutama siswa SMA dan kadang lebih memilih keluar dari desanya untuk ikut Bimbingan Belajar terutama mereka yang mampu.

2) Sebagian mereka kurang berminat dan kurang dimotivasi oleh keluarga.

3) Mereka lebih sering menunggu teman-temannya terutama kelompoknya, artinya, jika temannya ikut mereka juga ikut.

4) Adanya kegiatan pelajaran tambahan dari sekolah mereka sehingga waktu mereka untuk belajar di kampungnya tidak bisa.

Ketika kelompok belajar sudah dibentuk di kelurahan Bandungrejosari dan Bakalankrajan, dan para peserta dari siswa SD dan SMP berdatangan, para siswa SMA merasa sulit untuk bergaul 
dan bersosialisasi dengan adik kelasnya itu walaupun dalam bimbingan belajar ini tempat belajar dan tingkatan sekolahnya dibedakan.Jadi kalau dilihat dari jumlah tersebut, jumlah peserta dari siswa SD lebih banyak, kemudian diikuti oleh siswa-siswa SMP dan SMA.

Sebelum program bimbingan belajar diberikan kepada para siswa-siswa yang sudah terbentuk dalam kelompokkelompok belajar, maka tes awal (pretest) diberikan untuk mengetahui tingkat kemampuan awal siswa. Cara ini dilakukan agar apabila diberikan perlakuan, maka hasil tes akhir (posttest) nantinya akan dikurangi dengan hasil tes awal (pretest) dapat diketahui tingkat kemajuan dalam prestasi belajar siswasiswa SD, SMP, dan SMA dalam mengikuti program bimbingan belajar. Berikut ini adalah hasil tes awal (pretest) dan tes akhir (posttest) peserta program bimbingan belajar di Kelurahan Bandungrejosari dan Bakalankrajan kecamatan Sukun Malang.
B. Hasil Prestasi Belajar dalam Program Bimbingan Belajar

Prestasi belajar dalam program IbM ini didahului dengan pemberian test awal (pretest) untuk mengetahui kemampuan awal peserta kemudian diikuti oleh pemberian tes akhir (posttest) untuk mengetahui tingkat keberhasilan akhir setelah diberi perlakuan berupa program bimbingan belajar untuk seluruh jenjang dan tingkatan sekolah dari SD, SMP, dan SMA di Kelurahan Bandungrejosari dan Kelurahan Bakalankrajan Kecamatan Sukun Malang. Berikut ini hasil test awal (pretest) dari kelurahan Bandungrejosari dan Bakalankrajan kecamatan Sukun Malang.

Berikut ini adalah jumlah kelompok belajar dapat dilihat pada Tabel 1dan hasil tes awal (pretest) dan tes akhir (posttest) dapat dilihat pada Tabel 2 untuk peserta kelompok belajar dari siswa SD, SMP, dan SMA kelurahan Bandungrejosari dan kelurahan Bakalankrajan kecamatan Sukun Malang.

Tabel 1. Jumlah Kelompok Belajar di Kelurahan Bandungrejosari dan Bakalankrajan Kecamatan Sukun Malang

\begin{tabular}{|c|c|c|c|c|c|c|c|}
\hline \multirow{3}{*}{$\begin{array}{c}\text { Kelura } \\
\text { Han }\end{array}$} & \multicolumn{6}{|c|}{ Jumlah Peserta dan Kelompok Belajar } & \multirow[b]{3}{*}{ Jadwal } \\
\hline & \multicolumn{2}{|c|}{ SD } & \multicolumn{2}{|c|}{ SMP } & \multicolumn{2}{|c|}{ SMA } & \\
\hline & $\begin{array}{l}\text { Jumlah } \\
\text { Peserta }\end{array}$ & $\begin{array}{l}\text { Kelom } \\
\text { pok } \\
\text { Belajar }\end{array}$ & $\begin{array}{l}\text { Jumlah } \\
\text { Peserta }\end{array}$ & $\begin{array}{l}\text { Kelom } \\
\text { pok } \\
\text { Belajar }\end{array}$ & $\begin{array}{l}\text { Jumlah } \\
\text { Peserta }\end{array}$ & $\begin{array}{c}\text { Kelom } \\
\text { pok } \\
\text { Belajar }\end{array}$ & \\
\hline $\begin{array}{l}\text { Bandung } \\
\text { Rejosari }\end{array}$ & $\begin{array}{c}72 \\
\text { siswa }\end{array}$ & $\begin{array}{l}7 \text { kelom } \\
\text { Pok }\end{array}$ & 11 siswa & $\begin{array}{l}1 \text { kelom } \\
\text { pok } \\
\text { belajar }\end{array}$ & 9 siswa & $\begin{array}{l}1 \text { kelom } \\
\text { pok } \\
\text { belajar }\end{array}$ & \multirow{3}{*}{$\begin{array}{l}\text { Setiap hari } \\
\text { kecuali } \\
\text { hari Ming } \\
\text { gu jam } \\
14.30- \\
17.30 \\
\text { dan } 18.15 \\
-21.00 \\
\text { WIB }\end{array}$} \\
\hline $\begin{array}{c}\text { Bakalan } \\
\text { Krajan }\end{array}$ & $\begin{array}{c}66 \\
\text { siswa }\end{array}$ & $\begin{array}{c}5 \text { kelom } \\
\text { Pok }\end{array}$ & 7 siswa & $\begin{array}{l}1 \text { kelom } \\
\text { pok } \\
\text { belajar }\end{array}$ & 5 siswa & $\begin{array}{l}1 \text { kelom } \\
\text { pok } \\
\text { belajar }\end{array}$ & \\
\hline Jumlah & $\begin{array}{c}138 \\
\text { siswa }\end{array}$ & $\begin{array}{l}12 \text { kelom } \\
\text { pok } \\
\text { belajar }\end{array}$ & 18 siswa & $\begin{array}{l}2 \text { kelom } \\
\text { pok } \\
\text { belajar }\end{array}$ & $\begin{array}{c}14 \\
\text { siswa }\end{array}$ & $\begin{array}{l}2 \text { kelom } \\
\text { pok } \\
\text { belajar }\end{array}$ & \\
\hline & & & & $s^{\circ}$ & & & \\
\hline
\end{tabular}


Tabel 2. Hasil Tes Awal (Pretest) dan Tes Akhir (Posttest) Peserta Kelompok Belajar

\begin{tabular}{|l|c|c|c|c|c|c|}
\hline \multirow{2}{*}{ KELURAHAN } & \multicolumn{5}{c|}{ JENJANG SEKOLAH } \\
\cline { 2 - 7 } & \multicolumn{2}{|c|}{ SD } & \multicolumn{2}{c|}{ SMP } & \multicolumn{2}{c|}{ SMA } \\
\cline { 2 - 7 } & Pretest & Posttest & Pretest & Posttest & Pretest & Posttest \\
\hline Bandungrejosari & 36,38 & 70,69 & 40,45 & 70,62 & 40 & 70 \\
\hline Bakalankrajan & 41,36 & 70,22 & 44,28 & 73,57 & 34 & 71,25 \\
\hline
\end{tabular}

A. Pembentukan Kelompok Belajar

Berdasarkan hasil yang telah dipaparkan di atas terkait dengan persiapan, sosialisasi, dan pelaksanaan pembentukan kelompok belajar dan program bimbingan belajar serta hasil akhir yang telah dicapai, maka secara keseluruhan kegiatan ini dapat berjalan dengan sukses dan mendapat simpati dan dukungan dari kelurahan Bandungrejosari dan Bakalankrajan, lembaga pendidikan seperti sekolahsekolah di kelurahan tersebut, para tokoh masyarakat, orang tua siswa dan warga masyarakat.

Berdasarkan hasil kegiatan ini, Tim IbM dapat mengajak 15 wakil warga dari kelurahan Bandungrejosari dan kelurahan Bakalankrajan kecamatan Sukun Malang. Mereka adalah Mitra kerja Tim IbM yang dapat bekerja sama dalam mensukseskan pembentukan kelompok belajar dan program bimbingan belajar di kelurahannya. Oleh karena itu, tugas Tim IbM adalah memberikan pelatihan dan pembekalan kepada 15 Mitra kerja IbM tersebut tentang teknik dan metode pembelajaran, pembuatan silabus materi ajar, dan penyusunan materi ajar bagi siswa SD, SMP, dan SMA dalam program bimbingan belajar.

Sebagaimana yang telah direncanakan sejak awal, kegiatan pembentukan kelompok belajar ini hanya difokuskan pada peserta dari siswa SMP dan SMA karena alasan waktu dan tenaga yang terbatas. Tetapi ketika sosialisasi telah berlangsung dan pendataan peserta telah dilakukan, banyak permintaan dari masyarakat 2 kelurahan Bandungrejosari dan Bakalankrajan agar dapat juga melibatkan siswa-siswa SD. Permintaan itu kami penuhi sehingga peserta dibuka secara bebas yang melibatkan siswasiswa dari SD, SMP, dan SMA. Dari hasil pendataan yang dilakukan, memang peserta yang paling banyak dari kalangan siswa SD hingga mencapai 138 orang, kemudian diikuti oleh siswa SMP yang berjumlah 18 orang, dan siswa SMA yang berjumlah 14 orang. Jumlah keseluruhan adalah 170 siswa. Dari hasil ini, siswa SMA dan SMP tidak sebanyak seperti siswa SD. Ada beberapa alasan mengapa siswa SMA dan SMP kurang begitu banyak :

1) Mereka merasa malu dan gengsi untuk datang ke tempat kelompok belajar di tempat sekitarnya terutama siswa SMA dan kadang lebih memilih keluar dari desanya untuk ikut Bimbingan Belajar terutama mereka yang mampu.

2) Sebagian mereka kurang berminat dan kurang dimotivasi oleh keluarga.

3) Mereka lebih sering menunggu teman-temannya terutama kelompoknya, artinya, jika temannya ikut mereka juga ikut.

4) Adanya kegiatan pelajaran tambahan dari sekolah mereka sehingga waktu mereka untuk belajar di kampungnya bersamaan sehingga mereka tidak tidak bisa mengikuti kelompok belajar dan bimbingan belajar. 
B. Hasil Prestasi Belajar dalam Program Bimbingan Belajar

Untuk mengetahui seberapa jauh keberhasilan prestasi belajarnya para peserta kelompok belajar, maka kegiatan ini dilengkapi dengan instrumen atau alat evaluasi yaitu berupa tes. Dalam hal ini ada 2 tes untuk mengetahui kemampuan para peserta bimbingan belajar yaitu tes awal (pretest) dan tes akhir (posttest) yang diujikan kepada semua peserta kelompok belajar di kelurahan Bandungrejosari dan kelurahan Bakalankrajan kecamatan Sukun kota Malang.

Pertama, evaluasi untuk mengetahui kemampuan awal peserta kelompok belajar adalah dengan memberikan tes awal kemudian dilanjutkan dengan pemberian perlakuan (treatment) berupa program bimbingan belajar selama 3 bulan lebih dari tanggal 1 September hingga tanggal 29 November 2014. Diakhir program kegiatan, para peserta kelompok belajar dari SD hingga SMA diberi tes akhir (posttest) untuk mengetahui tingkat keberhasilan pencapaian peserta selama mengikuti kelompok belajar dan program bimbingan belajar.

Berdasarkan nilai pada tabel di atas, dapat disimpulkan siswa SD, SMP, dan SMA setelah mengikuti kelompok belajar dan program bimbingan belajar (Bimbel) dapat meningkatkan prestasi belajarnya. Dengan demikian, pembentukan kelompok belajar dan program bimbingan belajar memberikan pengaruh yang signifikan. Ini terlihat nilai tes akhir (posttest) jauh lebih tinggi daripada nilai tes awal (pretest) pada semua tingkatan atau jenjang sekolah di atas.

\section{KESIMPULAN}

Berdasarkan deskripsi di atas, dapat disimpulkan bahwa hasil yang dicapai dalam IbM pembentukan kelompok belajar dan pemberian bimbingan belajar (Bimbel) di kelurahan Bandungrejosari dan Bakalankrajan, Sukun Malang menunjukkan keberhasilan yang baik. Hal ini dapat dilihat dari persiapan dan pelaksanaan program bimbingan belajar serta hasil akhir yang dicapai.

Pertama, IbM ini telah berhasil dalam melakukan persiapan yang baik dalam melakukan pembentukan kelompok belajar dan pemberian program bimbingan belajar kepada siswa SD, SMP, dan SMA, khususnya pada mata pelajaran (1) Bahasa Indonesia, (2) Matematika, dan (3) Bahasa Inggris. Persiapan ini telah ditandai dengan adanya sosialisasi yang terorganisir dan terorganisasi yang sistematis sehingga informasi-informasi penting dapat tersampaikan kepada seluruh warga kelurahan Bandungrejosari dan kelurahan Bakalankrajan kota Malang. Oleh karena itu, program ini mendapat dukungan penuh dari kelurahan Bandungrejosari dan Bakalankrajan, sekolah-sekolah setempat, ketua RW dan RT, tokoh masyarakat, orang tua siswa dan seluruh warga 2 kelurahan tersebut. Selain itu, Tim IbM telah memberikan pelatihan dan pembekalan kepada 15 Mitra Kerja yang berasal dari warga masyarakat itu sendiri yang terkait dengan metode atau teknik pembelajaran, penyusunan silabus, dan pengembangan materi ajar untuk program bimbingan belajar. Persiapan dapat diwujudkan dengan dimulainya program bimbingan belajar pada 1 September 2014 hingga pada bulan Desember 2014.

Kedua, pelaksanaan bimbingan belajar yang diawali dengan pembentukan kelompok belajar dapat berjalan dengan baik dan menunjukkan pencapaian yang maksimal. Ini terbukti dengan adanya kerja sama yang baik dan berhasil antara Tim IbM dan Mitra kerja sebanyak 15 orang yang berasal dari 2 kelurahan tersebut. Dengan adanya kerja sama yang terkoordinatif ini, Tim IbM dan para Mitra dapat membentuk 16 kelompok belajar dengan jumlah peserta 170 orang yang berasal dari siswa SD, 
SMP, dan SMA yang tersebar di kelurahan Bandungrejosari dan kelurahan Bakalankrajan kota Malang.

Ketiga, ketika kegiatan bimbingan belajar ini berlangsung, maka Tim IbM dan Mitra Kerja telah memberikan 2 macam tes yaitu tes awal (pretest) dan tes akhir (posttest). Kegiatan ini bersifat wajib dilaksanakan dalam artian bahwa tes awal (pretest) diberikan untuk mengukur kemampuan awal siswa dan tes akhir (posttest) diberikan untuk mengukur hasil akhir yang telah dicapai. Berdasarkan analisis hasil test, ditemukan program pembentukan kelompok belajar dan pemberian program bimbingan belajar memberikan pengaruh yang signifikan karena hasil tes akhir (posttest) peserta jauh lebih baik daripada hasil tes awal (pretest) untuk semua tingkatan sekolah dan kelas baik di kelurahan Bandungrejosari maupun kelurahan Bakalankrajan kecamatan Sukun kota Malang.

\section{REFERENSI}

Degeng, N. S. 2001. Pedoman Penulisan Bahan Ajar. Malang: LP3 Universitas Negeri Malang.

Departemen Pendidikan Nasional. 2002. Pendekatan Kontekstual: Contextual Teaching and Learning. Jakarta: Direktorat PLP.

Departemen Pendidikan Nasional. 2008. Panduan Pengembangan Materi Pembelajaran. Direktorat Jenderal Manajemen Pendidikan Dasar dan Menengah. Direktorat Pembinaan Sekolah Menengah Atas
Kemendikbud, 2013. Panduan Pelaksanaan Penelitian dan Pengabdian Kepada Masyarakat di Perguruan Tinggi. Edisi IX. Direktorat Penelitian dan Pengabdian Kepada Masyarakat Direktorat Pendidikan Tinggi.

Nurhadi, dkk. 2004. Pembelajaran Kontekstual dan Penerapannya dalam KBK. Malang: Universitas Negeri Malang.

http://regional.kompas.com/read/2012/05 /26/15323945/Disuntik.Dana.Rp.144 .Miliar.UN.Kota.Malang.Jeblok.

http://www.malang-post.com/14-Juni2014/pendidikan/87902-hasil-iniawal-perjuangan-selanjutnya http://surabaya.bisnis.com/read/2014052

0/4/71557/pengumuman-un-smaada-5-siswa-swasta-di-malang-tidaklulus.

(http://file.upi.edu/Direktori/FIP/JUR.P SIKOLOGI_PEND_DAN_BIMBIN GAN/195903311986031SUHERMAN/Bimbingan_Belajar.p df).

Supina dan Parmi Ismu Tri. 2011. Pengembangan Pendidikan Budaya dan Karakter Bangsa melalui Pembelajaran Matematika di SD. Badan Pengembangan Sumber daya Manusia Pendidikan dan Penjaminan Mutu Pendidikan. Kementerian Pendidikan Nasional.

Undang-undang Republik Indonesia No. 20 Tahun 2003 Tentang Sistem Pendidikan Nasional. Bandung: Citra Umbara. 